\title{
VERIFICATION OF MOLECULAR-BASED TESTING PLATFORM FOR THE DETECTION OF MYCOPLASMA GENITALIUM
}

\author{
Authors: Emma Fitzpatrick ${ }^{1}$, Allison Waters ${ }^{1}$, Christina Byrne ${ }^{1}$, Derek Freedman ${ }^{2}$, Cillian De Gascun ${ }^{1}$ \\ Affiliations: ${ }^{1}$ UCD National virus Reference Laboratory, Belfield Campus, Dublin 4, IRELAND and \\ ${ }^{2}$ STI Clinic, 88 Ranelagh Village, Dublin 6, D06 Y2W6
}

AIM: INTRODUCE MYCOPLASMA GENITALIUM TESTING AT THE NATIONAL VIRUS REFERENCE LABORATORY

\section{INTRODUCTION}

- Mycoplasma genitalium (MG) is a sexually transmitted infection (STI) associated with a wide range of clinical conditions including cervicitis, endometritis, non-gonococcal urethritis and pelvic inflammatory disease.

- The fastidious requirements for culturing Mycoplasma, mean that molecular methods are now recommended for testing clinical specimens.

- Studies have calculated an MG prevalence of approximately $1 \%$ in the general screening population and rates ranging between $9 \%$ to over $50 \%$ in high risk populations.

- Current MG guidelines recommend treating with an extended course of macrolide antibiotics. However, antibiotic resistance is increasing and detection alone may not be sufficient to guide treatment.
FIGURE 1. Summary of study methodology

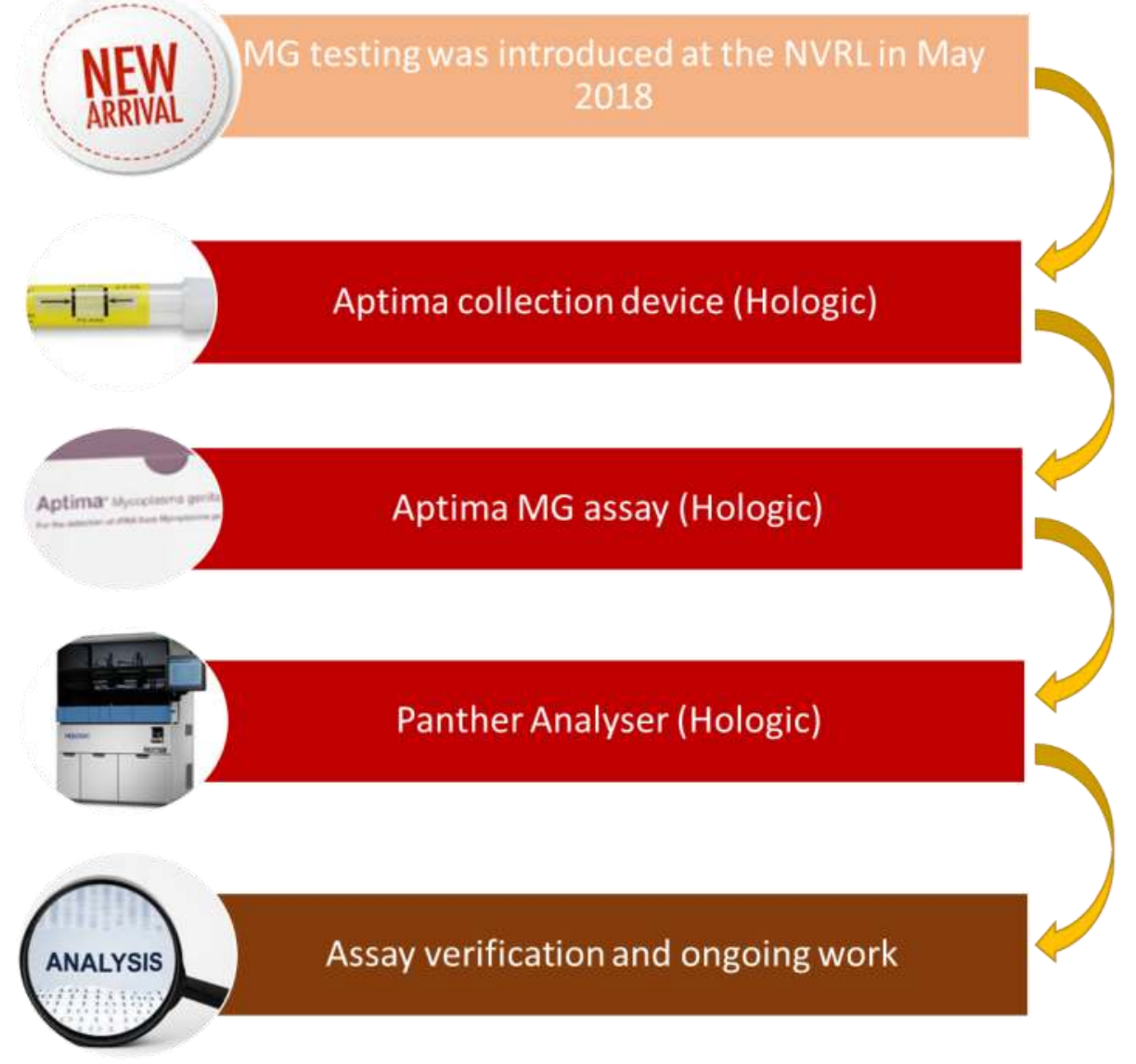

RESULT - VALIDATION OF THE APTIMA M. GENITALIUM

\section{ASSAY}

TABLE 1. Performance of the Aptima MG assay

\begin{tabular}{|c|c|c|c|c|}
\hline & \multirow{2}{*}{ ROUTINE TESTING } & \multicolumn{2}{|c|}{ ASSAY VALIDATION } & \\
\hline & & Clinical Validation & $\begin{array}{c}\text { Technical } \\
\text { Validation panel }\end{array}$ & \multirow{3}{*}{$\begin{array}{l}\text { MG testing } \\
\text { requested }\end{array}$} \\
\hline $\mathrm{N}$ & 140 & 450 & 20 & \\
\hline $\begin{array}{l}\text { Specimen } \\
\text { population }\end{array}$ & $\begin{array}{l}\text { MG testing } \\
\text { specifically } \\
\text { requested by } \\
\text { clinician }\end{array}$ & $\begin{array}{l}\text { Consented non- } \\
\text { targeted MG } \\
\text { screening with } \\
\text { clinical partner }\end{array}$ & Non Clinical & \\
\hline Sample types & $\begin{array}{l}\text { Anogenital swabs } \\
\text { Urine }\end{array}$ & $\begin{array}{l}\text { All specimens } \\
\text { types }\end{array}$ & Bacterial Culture & $\begin{array}{l}\text { Clinical } \\
\text { Validation }\end{array}$ \\
\hline $\begin{array}{l}\text { Time frame } \\
\text { (months) }\end{array}$ & 3 & 4 & N/A & \\
\hline MG Detection & 4 & 4 & 20 & \\
\hline MG Not Detected & 136 & 446 & 0 & \\
\hline Resistant & $\begin{array}{c}1 \text { out of } 2 \text { MG } \\
\text { positive specimens } \\
\text { tested }\end{array}$ & Unknown & Unknown & \\
\hline MG Incidence & $\begin{array}{c}2.86 \% \\
{[95 \% \mathrm{Cl} 0.78 \% \text { to }} \\
7.15 \%]\end{array}$ & $\begin{array}{c}0.89 \% \\
{[95 \% \mathrm{Cl} 0.24 \% \text { to }} \\
2.26 \%]\end{array}$ & $100 \%$ & \\
\hline
\end{tabular}

TABLE 2. Clinical Specimens with detectable Mycoplasma genitalium

\begin{tabular}{c|c|c|c|c|c|}
\hline & Gender & $\begin{array}{c}\text { Sample } \\
\text { type }\end{array}$ & $\begin{array}{c}\text { Clinical } \\
\text { details }\end{array}$ & $\begin{array}{c}\text { AGE } \\
\text { (yrs) }\end{array}$ & $\begin{array}{c}\text { Antibiotic } \\
\text { susceptibility }\end{array}$ \\
\hline MG testing & $\mathrm{M}$ & Unal Swab & MSM & 34 & Susceptible \\
\hline requested & $\mathrm{M}$ & Urine & Urethritis & 24 & - \\
\hline & $\mathrm{F}$ & Swab & $\begin{array}{c}\text { Boyfriend } \\
\text { NGU }\end{array}$ & 25 & Resistant \\
\hline Clinical & $\mathrm{M}$ & Urine & Urethritis & & \\
\hline Validation & $\mathrm{M}$ & Urine & Urethritis & & \\
\hline & $\mathrm{M}$ & Throat & Urethritis & & \\
\hline & & Swab & - & & \\
\hline & & & & \\
& & & &
\end{tabular}

Approximately $3 \%$ of all patient specimens specifically requesting Mycoplasma genitalium testing have been positive since the assay was introduced.

\section{TAKE HOME MESSAGES ...}

- The estimated incidence of MG infection from the present study is as expected for a non-targeted general screening population.

- MG testing is now available by request at the NVRL in 2018.

- Confirmation of all positive results, as well as reflex antibiotic resistance screening will be carried out on all MG detections 